\title{
Los muros fronterizos. Una aproximación jurídica a la luz de los derechos humanos
}

\author{
Alessandra Enrico Headrington*
}

\begin{abstract}
RESUMEN
El presente artículo tiene como objetivo analizar la problemática actual de la construcción de muros fronterizos. En particular, se propone un abordaje desde la perspectiva jurídica a fin de comprender si estos objetos pueden entrañar consecuencias en el ejercicio de derechos de los individuos. Para tales efectos, se ha estudiado este fenómeno a partir de consideraciones históricas y políticas, cuestionando cómo a partir de la caída del muro de Berlín y el inicio de la globalización estos se erigen como principal contradicción de un mundo que se predica más abierto. Asimismo, se ha desarrollado cuáles son los contextos y justificaciones generales que han hecho que los Estados vuelvan a construir muros en sus fronteras.

A partir de ello, se han planteado dos argumentos que se encuentran en constante tensión. De un lado, la apelación a la soberanía estatal, y de otro lado, los derechos humanos de aquellos que se encuentran en dicho espacio limítrofe. En esa línea, se plantea la evolución de la soberanía estatal conjuntamente con el proceso de humanización del derecho internacional.

Finalmente, se han enunciado aquellos criterios por los cuales un Estado podría incurrir en responsabilidad internacional, concluyéndose que, frente a la eventual vulneración de un derecho, tal como el derecho a la vida o integridad, se satisface el primero de los criterios que es el hecho ilícito internacional. Y, el segundo criterio, el de atribución, se vería satisfecho, siempre que su construcción haya sido ordenada por algún órgano del mismo Estado. Indudablemente este análisis exige una constatación casuística y fáctica a fin de determinar si un muro fronterizo per se genera responsabilidad internacional.
\end{abstract}

\footnotetext{
* Abogada por la Pontificia Universidad Católica del Perú (PUCP), cursó estudios en la Escuela de Derecho de la Universidad Carlos III de Madrid. Se desempeńó como investigadora en el Instituto de Democracia y Derechos Humanos de la PUCP y trabajó como oficial de elegibilidad de solicitudes de refugio en la Subdirección de Derecho Internacional de los Refugiados de la Dirección de Derechos Humanos del Ministerio de Relaciones Exteriores del Perú. Actualmente es asociada de protección (legal) en el ACNUR - Lima y cursa estudios en la Maestría de Derechos Humanos de la PUCP. Correo electrónico: alessandra.enrico@pucp.pe

Las opiniones vertidas en este artículo son a título individual y no institucional.
}

iD https://orcid.org/0000-0002-4260-5679 
Palabras clave: Muro fronterizo, globalización, derechos humanos, fronteras, consecuencias jurídicas, soberanía, jurisdicción, responsabilidad internacional

\section{Border walls. A legal approach in light of the human rights}

\section{Abstract}

The objective of this article is to analyze the complex problem of border walls. Specifically, it introduces a legal lens to the issue in order to determine whether these border walls could affect the exercise of individual human rights. With this purpose in mind, the phenomenon of border walls is examined from historical and political perspectives, concluding that since the fall of the Berlin wall and the advent of globalization, these physical barriers stand as a significant contradiction to a world that is supposedly freer and more open. It also purports to examine the general social contexts and justifications that explain why states resort to building walls on their borders.

The article then addresses the constant tension between two considerations: on the one hand, the appeal to state sovereignty, and on the other, the human rights of the particular people and communities on the border lines. It emphasizes that state sovereignty must evolve in conjunction with the humanization of international law.

Finally, the article discusses the two required elements to establish state responsibility in the context of border walls. For example, the commission of a wrongful act, such as the violation of the right to life or the right to physical integrity, constitutes a breach of an international obligation, which satisfies the first requirement to establish state responsibility. To fulfill the second requirement, the wrongful act must be attributed to the state, which is possible if the order for construction qualifies as a governmental act. That being said, a finding of state responsibility in this context per se is inevitably a case-specific analysis.

Key words: Border Wall, globalization, human rights, frontiers, legal consequences, sovereignty, jurisdiction, international responsibility

\section{Introducción}

En el presente artículo se abordará una problemática que lleva ya larga data pero que en la actualidad tiene un eco cada vez más importante: la construcción de muros fronterizos. Esta realidad se configura como la respuesta más rápida y pragmática que muchos Estados han encontrado para dar solución a situaciones muchas veces incontenibles, tales como la creciente afluencia migratoria o la comisión de actos de terrorismo.

Para comprender este fenómeno es imprescindible remontarse al que quizás sea el antecedente más recordado de un muro fronterizo hostil, el que se construyó en Berlín, entre la República Democrática Alemana (RDA) y la República Federal Alemana (RFA). No obstante, debe destacarse que este no es, ni de cerca, el primero de los muros que se erigieron en la historia universal. Basta enunciar construcciones 
que datan desde las murallas de Babilonia (años VIII al V a.C.) (Montero, 2012, p. 175), la Gran Muralla China (año 215 a.C) (Shelley, 2015, pp. 92, 93), e incluso el muro de Adriano (año 122 d.C) (Gargantilla, 2016), hasta la época más reciente en donde se ha constatado que estos se han multiplicado.

Sin ir muy lejos, hoy en día en la región americana cada vez se habla con mayor autoridad de la ampliación del muro fronterizo construido en la frontera entre Estados Unidos y México, junto con la agudización de las políticas migratorias entre ambos países y en Centroamérica, que incluyen también la construcción de barreras o alambradas (Villegas y Semple, 1 de febrero de 2019). No obstante, este no es el único muro en la región, existe también un muro construido entre México y Guatemala y, hasta hace casi un año, Ecuador había planificado la construcción de un muro en la frontera con Perú (frontera de Huaquillas y Aguas Verdes), el cual fue finalmente paralizado por presión diplomática (Riepl, 10 de julio de 2017).

Todo ello, evidentemente, ha exigido un estudio acucioso desde diversas disciplinas. En esa medida, distintas aproximaciones han intentado dar respuesta a este fenómeno: la historia, las ciencias sociales y políticas, las relaciones internacionales, e incluso la psicología. Es por ello que en las siguientes secciones se planteará la necesidad de abordar esta problemática desde el derecho, en particular desde el derecho internacional. Para tales efectos, se analizarán las consecuencias jurídicas o impactos que estos objetos pueden tener en el ejercicio de derechos de los individuos.

Como se verá, este fenómeno da cuenta de dos argumentos que se encuentran en tensión, de un lado, la apelación al concepto de soberanía conjuntamente, y de otro lado, el proceso de humanización del derecho internacional. Estos dos aspectos permitirán comprender cuándo un muro, aun cuando se encuentra construido en el territorio del propio Estado, podría ser considerado ilegal por la eventual vulneración de derechos. Y, por lo tanto, ello conllevaría, como consecuencia necesaria, la formulación de un análisis sobre la determinación de la responsabilidad internacional del Estado que lo construyó.

Finalmente, el término «muro» al que se hará referencia se utilizará para definir a todos aquellos objetos físicos que dividen fronteras. Entre los más comunes se pueden encontrar las cercas, vallas, alambradas o las barreras. Todos estos se caracterizan por contar con estructuras de concreto que sirven para separar y diferenciar a unos de aquellos. En la misma línea, en el derecho internacional, también se ha utilizado la acepción «muro» para denominar a los objetos de división construidos en las fronteras de los Estados. Esto ha sido señalado explícitamente por la Corte Internacional de Justicia (CIJ) en la opinión consultiva relativa a las consecuencias jurídicas de la construcción de un muro en el territorio palestino ocupado. 


\section{Estado de la cuestión: ¿̨cuántos y qué tipos de muros se han construido en la actualidad?}

De acuerdo a una investigación conducida, en la actualidad existen cerca de setenta muros fronterizos entre construidos, anunciados o paralizados en las fronteras de los Estados (Enrico, 2019). Estos pueden clasificarse en dos tipos de acuerdo al contexto en el que se erigen. De un lado, aquellos construidos en contextos de ocupación, como el muro entre el Sahara Occidental y Marruecos, y un muro sobre el que el derecho internacional se ha pronunciado, por ejemplo, en el caso del muro construido entre territorios ocupados palestinos e Israel. De esta manera, en el ańo 2004 la CIJ en el marco de su competencia consultiva desarrolló las consecuencias del muro construido en un contexto sui generis que es la de un régimen de ocupación de los territorios ocupados palestinos.

En este documento jurídico la CIJ desarrolló las implicancias jurídicas de la presencia de un muro fronterizo, principalmente en el ejercicio de derechos de la población palestina. Así, dicha opinión consultiva indicó, dentro de sus alcances que:

39. En el presente caso, si la Asamblea General pide a la corte que determine las consecuencias jurídicas derivadas de la construcción del muro, el uso de estos términos implica necesariamente una evaluación sobre si dicha construcción viola o no ciertas normas y principios del derecho internacional. (CIJ, 2004, p. 39)

$\mathrm{Y}$, de otro lado, se encuentra una vasta mayoría de muros fronterizos construidos en otras situaciones de conflicto armado y en tiempos de paz. En estos contextos, los muros parecerían estar justificados toda vez que no se construyen en un territorio ajeno, como en los casos de ocupación, sino más bien se encuentran construidos en el territorio del propio Estado. Algunos ejemplos de estos son, el tramo de muro construido entre Estados Unidos y México, el muro entre México y Guatemala, o el que se encuentra entre Hungría y Croacia.

\section{Las fronteras: una aproximación interdisciplinaria}

El desarrollo de las implicancias de un muro fronterizo exige como punto de partida un estudio de las fronteras, su definición, cuáles son las principales dinámicas que ahí se llevan a cabo y cuál es su función acorde al contexto de las relaciones entre los Estados. Dicho ello, las fronteras, han estado presentes desde antes de la formación y consolidación de los Estados. Sin embargo, para efectos de delimitar su conceptualización, se partirá desde una aproximación histórica y política.

Su creciente importancia surge a raíz de la aparición de los Estados Nación, es decir, data del fin de la guerra de los 30 ańos y la Paz de Westfalia, en 1648. Tras la 
consolidación de estas nuevas entidades, nuevos límites comenzaron a trazarse para establecer la porción de territorio que cada Estado tendría, que se constituiría en el espacio en donde desplegaría su soberanía. Con esta concepción, surge también la consolidación de la soberanía sobre un espacio determinado, lo cual originó las «distintas luchas por la conquista de territorio y de grupos humanos para el desarrollo progresivo de los Estados» (Diesbach de Rochefort, 2002, pp. 17-18).

En esa línea, un primer gran hallazgo de la aproximación histórico-política es que las fronteras se consolidaron tras un periodo bélico y fueron establecidas como resultado del acuerdo entre dos o más Estados. No obstante, como se verá más adelante, esta concepción rígida ha ido transformándose gracias al fenómeno de la globalización. Este ha propuesto, desde su concepción, una mayor flexibilización del concepto mismo de frontera, haciendo que estas se difuminen paulatinamente para dar paso a dinámicas de mayor intercambio y cooperación entre los Estados. Conforme ha desarrollado Zapata, estos espacios limítrofes «han dejado de ser entendidos como meras líneas fijas geográficas y han comenzado a ser entendidas como el resultado de un proceso dinámico, como una realidad construida política y socialmente y en permanente cambio en cuanto a su gestión de la movilidad humana» (Zapata Barrero, 2012, p. 40).

Es en esa medida que se habla de un creciente número de dinámicas que se dan en el ámbito fronterizo, algunas que evidencian una mayor cooperación que otras. Sin embargo, para efectos del análisis de la legalidad de los muros fronterizos, se estudiarán aquellos espacios más bien hostiles, en donde las relaciones de los Estados se han visto deterioradas y el intercambio es prácticamente nulo por la presencia de este objeto. En palabras de Martínez (1994), en estos contextos existe una escasa relación entre Estados, por lo que las fronteras se denominan «alienadas». Esto implica:

Condiciones extremadamente desfavorables como la guerra, las divergencias políticas, el creciente nacionalismo, la animosidad ideológica, las disputas religiosas, la disimilitud cultural y la rivalidad étnica. Dichos factores constituyen las causas principales de tal alienación, y este clima lleno de tensión interfiere e impide que las poblaciones locales puedan estrechar vínculos de cooperación. (p. 2, traducción propia)

Algunos ejemplos actuales de este tipo de fronteras son las de Arabia Saudita y Yemen, Estado en el cual actualmente se libra un conflicto armado no internacional (Rule of Law in Armed Conflicts, 2018). De igual manera, un ejemplo actual de frontera alineada es el de India y Pakistán en donde recientemente se ha evidenciado una escalada de tensiones en la zona de Cachemira (Antońanzas, 28 de febrero de 2019).

Teniendo presente el necesario análisis contextual que debe realizarse a partir de las relaciones que se llevan a cabo en las zonas fronterizas, será necesario incorporar una visión o perspectiva adicional: la jurídica. Esta se encuentra referida principalmente 
a la delimitación de los márgenes del Estado con la finalidad de proteger el territorio, a la vez que permitirá comprender cuáles son los espacios en los que los Estados podrán desplegar su poder o autoridad. Como señalan Novak y García-Corrochano, «las fronteras señalan aquella porción del espacio terrestre que se haya bajo una determinada competencia estatal» (2016, p. 172). Dicho en otras palabras, la relevancia jurídica de las fronteras radica en el establecimiento de las competencias y el margen de actuación de los Estados el cual, como regla general, se debe circunscribir a su territorio. En ese orden de ideas, el establecimiento de las fronteras permite tener certeza jurídica en aquellos espacios sobre los que un Estado ejerce jurisdicción.

A modo de conclusión, importa destacar, cómo en el campo de lo práctico, se determina una frontera. De manera general, existen dos etapas importantes en este proceso. La primera de ellas se denomina delimitación y tiene como antecedente una aproximación más política, pues es el momento en el que dos o más Estados se ponen de acuerdo, negocian y determinan los límites que corresponderán a cada uno. Una segunda etapa es la demarcación, esta se trata de «una operación material y técnica que consiste en llevar la delimitación al terreno, inspeccionando el territorio, realizando las mediciones y levantamientos topográficos necesarios, y por último, señalando los puntos por donde pasa la frontera con elementos visibles» (Novak y García-Corrochano, 2016, p. 175). Este proceso de demarcación, por lo general, se encuentra establecido en el instrumento convencional suscrito por dos o más Estados, por medio del cual se establecen las fronteras entre los mismos.

\section{Principales razones por las que los Estados construyen muros}

Conforme se ha anticipado, el incremento exponencial de muros fronterizos interpela las razones mismas de la globalización que, entre otros presupuestos, tiene que ver con la apertura hacia un mundo más interconectado. Así, algunos de los hechos históricos que marcaron un antes y un después en este tránsito hacia un mundo globalizado fueron la caída del muro de Berlín el 9 de noviembre de 1989, después de veintiocho años de construido, y en consecuencia la reunificación de la República Democrática Alemana (RDA) a la República Federal de Alemania (RFA) en 1990. Con ello como antecedente, en 1991 cayó el bloque soviético (URSS), y acabó la era del mundo bipolar. Estos grandes acontecimientos favorecieron un clima de distensión y promovieron una mayor cooperación.

En esa línea, la política de construir grandes y fortificadas barreras o muros en las fronteras fue tornándose anacrónica por ser contraria a los intereses primarios de la globalización: libre circulación, transporte de mercancías y, en general, intercambio a todo nivel. «Esta relación cada vez más estrecha y de interdependencia que empezó 
a forjarse entre los Estados, favoreció un vínculo de reciprocidad y empezó a tejer un vínculo de necesidad» (Enrico, 2019, p. 56). Entonces un muro fronterizo en la era post Berlín, representaba un óbice para el intercambio en todo nivel.

Podría señalarse, inclusive, que esta interconexión, la rápida fluidez de personas, capitales y comercios hizo que el tradicional concepto de Estado-nación, herencia de la era westfaliana, se vea fuertemente debilitado debido a las propias dinámicas interestatales. Frente a ello, el concepto de frontera se ha hecho cada vez más poroso al punto de ponderarse el intercambio y proponerse la creación de áreas comunes de libre tránsito. Un buen ejemplo de ello es el espacio Schengen, en la Unión Europea.

En esa línea, aunque en un primer momento el fenómeno de la globalización trajo réditos, lo cierto es que estas mismas dinámicas favorecieron la aparición de nuevos brotes conflictivos que terminaron cuestionando los propios alcances de dicho concepto. Concretamente, algunos de dichos fenómenos fueron la migración masiva de personas y el brote de nuevas formas de terrorismo. Sin lugar a duda, ambos fueron intensificándose conforme aumentó el descontento por lo que, un sector de la doctrina consideró, un reparto desigual de beneficios (Chomsky, 2005).

\section{a. El incremento de flujos migratorios}

En lo que respecta, por ejemplo, al incremento de los flujos migratorios debe anotarse que no se trata de un fenómeno nuevo, es decir, no se da con la globalización. Por el contrario, en «cada época de la historia, estos movimientos masivos de personas han sido diferentes, ya sea por las causas que las motivan, como por las principales modalidades que revisten, las consecuencias que entrańan, y la significación que se les atribuye» (Arango, 2007, p. 1). Frente al inicio de la era de la globalización y el impacto de la apertura fronteriza, los Estados de acogida de migrantes comenzaron a impulsar una serie de reformas que fueron desde el endurecimiento de sus políticas migratorias, hasta la construcción y fortalecimiento de muros en sus fronteras a fin de evitar el ingreso masivo de personas.

En esa línea, el endurecimiento fronterizo y el control de las políticas migratorias a partir de la construcción de muros fronterizos significaron una contradicción a los propósitos mismos de la globalización. Como señala Ortega, «estas murallas, vallas, barreras, cercas y fronteras fortificadas muchas veces son consideras los nuevos muros de la globalización» (2006). En consecuencia, se puede afirmar que, frente a un fenómeno que propugnaba un intercambio en el sentido más amplio del término, apareció otro que exigió a los Estados la imposición de nuevas restricciones, por ejemplo, la libre circulación de personas. 


\section{b. Nuevos brotes terroristas}

En cuanto al incremento de acciones terroristas, un hecho que marcó un antes y un después en la reconfiguración del paradigma de seguridad nacional fueron los ataques del 11 de septiembre de 2001 en Estados Unidos. Como respuesta a ello, tanto la comunidad internacional como los propios Estados empezaron a responder de manera contundente. De un lado, la Organización de las Naciones Unidas, mediante el Consejo de Seguridad, organismo encargado de mantener la paz y seguridad entre los Estados, se pronunció condenando dichos ataques y considerándolos como una amenaza a la paz y a la seguridad internacional ${ }^{1}$. De igual modo, se emprendieron acciones como la creación de un Comité en el seno del Consejo de Seguridad con la finalidad de supervisar el cumplimiento de los compromisos relativos a la lucha contra el terrorismo; y, la aceptación del uso del derecho de legítima defensa para que aquellos Estados que recibieran ataques armados pudiesen defenderse válidamente.

De otro lado, las políticas contra el terrorismo, emprendidas en el marco del derecho interno de los Estados incluyeron un retorno al fortalecimiento de sus fronteras y políticas migratorias. Por ejemplo, Estados Unidos anunció un cambio en su política migratoria y que a raíz de dichos ataques iniciaría la llamada "guerra contra el terrorismo", discurso bajo el cual se justificaron acciones represivas contra Estados de Medio Oriente como Afganistán, y más adelante contra Iraq (Fidler, 2004).

Así, tanto el fenómeno migratorio como la denominada guerra contra el terrorismo se constituyeron en espacios que terminaron generando un endurecimiento de las fronteras, la ralentización de las economías y un menor intercambio de dinámicas entre los Estados. Todo ello significó un retorno y legitimación de aquellas razones que otrora conllevaron a la construcción de bloques de concreto en las fronteras o límites territoriales de los Estados. Junto con los fenómenos antes descritos, surgió lo que algunos antropólogos califican como un rechazo por lo externo o lo foráneo, lo cual incentivó, y aún hoy continúa incentivando, un discurso supremacista o xenófobo contra quienes no pertenecen a una misma nación.

De esta manera, la percepción del extranjero empezó a cambiar, y a ser visto con desconfianza, asociándolo a una amenaza tanto para los nacionales de un Estado, en el ejercicio de derechos, como para los propios Estados de acogida, en cuanto a mayores posibilidades de atentar contra su seguridad nacional. Todo ello, de acuerdo con Lisón Tolosana, marcaría una división y diferenciación basada en criterios como

\footnotetext{
1 Véase más en: Resoluciones de Consejo de Seguridad S/RES/1368 (2001) «Condena de los atentados cometidos el 11 de septiembre contra los Estados Unido»; S/RES/1373 (2001) «Creación del Comité contra el Terrorismo»; S/ RES/1377 (2001) «Declaración ministerial sobre la acción mundial para combatir el terrorismo».
} 
la nacionalidad, fomentando a su vez el enfrentamiento y la oposición a partir del límite (1994).

Con ello presente, cabría formular la siguiente pregunta: ¿realmente los nuevos muros separan «al otro», y a «lo ajeno»? La respuesta es negativa. Y es que, aunque exista una división física que aparentemente impida el acceso, indudablemente el muro se enmarca en una lógica de transgresión; quiere decir que, lejos de contribuir con el propósito de separación, seguridad y contención migratoria, solo genera nuevas y más peligrosas formas de violación al mismo. Esto significa que, «ante la imposibilidad de cruzar la zona en donde se encuentra un muro, se buscarán nuevas rutas para poder atravesarlo, sea para migrar o para atentar contra la seguridad del Estado» (Enrico, 2019, p. 58).

En esa óptica, mientras más se refuerzan las defensas fronterizas, el muro pone al descubierto una vulnerabilidad subterránea pues se crean nuevas estrategias de elusión tales como redes de túneles, estratagemas y rutas de migración redibujadas que muestran cierto patrón (Vallet, 2014). Un ejemplo de ello son los túneles construidos en la Franja de Gaza, los cuales conectan con Egipto (Hecht, 24 de julio de 2014).

\section{Una aproximación jurídica a la materia: dos argumentos en tensión, soberanía y derechos humanos}

Habiendo hecho un repaso sobre el contexto general que rodea la construcción de muros en la actualidad y cómo en los últimos años se han multiplicado en las fronteras de los Estados, este acápite tiene como objetivo dar cuenta de que este fenómeno puede, dependiendo de un análisis casuístico, generar consecuencias jurídicas por su presencia. Como premisa inicial debe indicarse que no existe ninguna fuente jurídica a nivel de derecho internacional que proscriba o condene a un Estado por la construcción de un muro fronterizo. Dicho de otro modo, no existe obligación convencional ni consuetudinaria que vincule a un Estado para no hacerlo. No obstante, esto no quiere decir que la ausencia de regulación jurídica clara sea motivo suficiente para descartar su ilegalidad. Por el contrario, deben de analizarse todas aquellas implicancias jurídicas que se encuentran alrededor de un muro fronterizo. En este acápite se examinarán aquellas vinculadas al individuo.

El argumento tradicionalmente empleado por los Estados que construyen muros fronterizos, en su propio territorio, es el de la apelación a la soberanía estatal. La actuación de los Estados en el marco de su dominio reservado, como atributo indisponible de los mismos, ha sido la principal razón empleada para justificar la legalidad de su construcción. Ahora bien, ¿qué debe entenderse por dominio reservado? El dominio 
reservado, en palabras de Salmón abarca todas aquellas materias sobre las cuales ningún otro Estado tiene derecho a intervenir (2014, p. 73), esto es, la capacidad de toma de decisiones de manera autónoma e independiente, como, por ejemplo, lo tocante a la política migratoria.

Autores clásicos entendían por soberanía un cúmulo de atributos relacionados con la supremacía, que quiere decir que ningún poder es superior; la continuidad o permanencia en el tiempo; la capacidad de toma de decisiones, toda vez que no existe sumisión a la ley; un carácter absoluto y completo; la capacidad de ser intransferible; y una jurisdicción especificada, que solía asociarse a lo territorial (Brown, 2010, pp. 30-31). No obstante, hoy en día dicha concepción ha cambiado, autores más contemporáneos como Truyol y Serra abordan un concepto de soberanía que tiende más hacia lo funcional, es decir, que propone como contrapartida el cumplimiento de los deberes y obligaciones derivadas de tratados o normas consuetudinarias generales (Salmón, 2014, p. 67).

$\mathrm{Al}$ respecto, para comprender los alcances de este concepto como justificación para la construcción de un muro fronterizo, debe referirse que este atributo estatal se despliega en dos dimensiones: la soberanía interna y la soberanía externa. La problemática de los muros fronterizos tiene especial relación con la primera de las dimensiones, la cual hace referencia a la capacidad que tienen los Estados para desenvolverse al interior de su propio territorio. En esa línea, todas aquellas medidas adoptadas por el Estado tendrán como principal destinatario a sus nacionales. En términos políticos, esta dimensión también implica el manejo y organización de las instituciones gubernamentales, principalmente aquellas que tienen la capacidad de toma de decisiones. Precisamente, Nagan y Hammer destacan que, junto con la territorialidad, una de las manifestaciones más relevantes de la soberanía interna es el fortalecimiento de instituciones políticas al interior de cada Estado, que actúan bajo la autorización o fijación de competencias asignadas para la toma de decisiones sobre las instituciones de gobierno (2004, p. 153).

En el marco de la soberanía, la territorialidad es otra característica que debe ser cuestionada también. Esto debido a que casi la totalidad de los muros fronterizos - salvo los construidos en situaciones de ocupación o con consentimiento de un tercer Estado, como en Calais, Francia - son erigidos dentro del propio territorio del Estado. Esta disposición del propio territorio no exoneraría a los Estados de una eventual responsabilidad internacional, por el contrario, los comprometería, de manera más directa a examinar si dicho objeto divisorio permite el cumplimiento de obligaciones en materia de derechos humanos.

Así, la concepción que se tenía de soberanía no es la misma que se manejaba en el derecho internacional clásico, en donde los Estados eran considerados los únicos 
sujetos del derecho internacional, creadores y destinatarios de las normas jurídicas internacionales (Carrillo Salcedo, 2000, p. 70). Con el paso de los años, la aparición y consolidación de nuevos sujetos de derecho internacional tales como las organizaciones internacionales, los pueblos y el propio individuo han coadyuvado a la reinterpretación de tal concepto, tendiendo más hacia una compatibilización.

No obstante, lo anterior no significa, en modo alguno la erosión total de la soberanía, por el contrario, este atributo continúa siendo la piedra angular del derecho internacional, pues precisamente por ella es que los Estados han decidido contraer nuevas obligaciones. Todo ello ha generado, en palabras del profesor Carrillo Salcedo, una tensión dialéctica entre soberanía y derechos humanos. Esta tensión se resuelve considerando que, precisamente "por ser soberanos, los Estados han adquirido obligaciones internacionales en materia de derechos humanos respecto de la comunidad internacional en su conjunto» (2000, p. 70). En ese orden de ideas, debe considerarse que, con el paso de los años, el concepto de soberanía ha ido más bien reinterpretándose a la luz de las nuevas obligaciones suscritas por los Estados, concretamente, aquellas relacionadas al individuo.

Este marco teórico previo permite comprender por qué hoy en día resulta, por decirlo menos, cuestionable, la apelación a la soberanía para justificar la construcción de un muro fronterizo. Puede afirmarse, en consecuencia, que las nuevas obligaciones contraídas por los Estados limitarían, de cierta manera, el ejercicio de su soberanía. En ese sentido, en lo tocante a la protección del ser humano, «los Estados no pueden seguir siendo considerados unidades independientes e impermeables como en la era post Westfalia; por el contrario, tienen una capacidad de influenciar y ser influenciados por el contexto internacional en el que se encuentran» (Enrico, 2019, p. 88).

En lo que respecta al argumento sobre los derechos humanos, el análisis respecto de las nuevas obligaciones en esta materia exige agregar un componente nuevo: el proceso de humanización del derecho internacional. Abordar los alcances de este proceso en el desarrollo del derecho internacional, demanda entender que nuevas y múltiples relaciones surgieron en el seno de la sociedad internacional, principalmente aquellas que coadyuvaron a la consolidación de nuevos sujetos de derecho internacional.

Es en esa medida que se habla de la creación de un nuevo capítulo en el derecho internacional, el derecho internacional de los derechos humanos, que se relaciona de manera transversal con el respeto y garantía de los derechos de los individuos en todos los ámbitos, incluso en el referido a la seguridad nacional y a la política migratoria de los Estados. Algunos autores como Cassese (1993), Cançado Trindade (2006) y Meron (2006), destacan que dentro de las principales características del 
proceso de humanización se encuentra la proliferación de fuentes normativas de derechos humanos.

De igual manera, se empezaron a fortalecer y a forjar distintos sistemas de protección de derechos humanos tales como el sistema de Naciones Unidas, y sistemas regionales como el interamericano, el europeo y el africano. Así, nuevas convenciones o tratados que reconocieron dichas prerrogativas comenzaron a suscribirse por parte de los Estados en el marco de los mencionados sistemas de protección de derechos humanos y, por consiguiente, a volverse vinculantes para los mismos. Algunos ejemplos de instrumentos generales son el Pacto Internacional de Derechos Civiles y Políticos (PIDCP), gestada en el marco de Naciones Unidas, la Convención Americana sobre Derechos Humanos (CADH), el Convenio Europeo de Derechos Humanos (CEDH), y la Carta Africana de Derechos Humanos y de los Pueblos. De igual manera, tratados más específicos de protección de derechos humanos, cuyos titulares principales son poblaciones vulnerables, comenzaron también a forjarse.

Asimismo, la humanización puso también de relieve la subjetividad activa del individuo, es decir, la conquista de derechos frente a la comunidad internacional, lo cual supuso la capacidad del individuo de demandar al Estado (subsidiariamente) ante tribunales internacionales frente a la eventual vulneración de sus derechos contenidos en algún instrumento jurídico del que aquél es parte (Cançado Trindade, 2007). Por último, una manifestación adicional fue la consolidación de la subjetividad pasiva del individuo, que implicó la creación de un sistema punitivo universal, como la Corte Penal Internacional, capaz de determinar la responsabilidad penal internacional y juzgar la comisión de crímenes internacionales cometidos por el mismo.

Teniendo ello presente, se puede concluir que, gracias a la soberanía estatal, el proceso de humanización en el orden internacional ha ampliado los espacios a sujetos otrora inadvertidos, como el individuo, rompiendo con ello, el exclusivismo tradicional de los Estados como únicos sujetos del derecho internacional (Carrillo Salcedo, 2000). Esto tuvo un eco importante en distintos pronunciamientos de instancias internacionales. Por solo citar un ejemplo, la CIJ reconoció en la Opinión Consultiva sobre el Asunto de la reparación de los daños sufridos al servicio de las Naciones Unidas, de 1949, lo siguiente:

Los sujetos de derecho, en un sistema jurídico, no son necesariamente idénticos en cuanto a su naturaleza o a la extensión de sus derechos, y su naturaleza depende de las necesidades de la comunidad. El desarrollo del Derecho Internacional, a lo largo de su historia, ha sido influenciado por las exigencias de la vida internacional y el aumento progresivo de las actividades colectivas de los Estados ha hecho ya surgir ejemplos de acción en el plano internacional por ciertas entidades que no son Estados. 
En esa medida, hoy el individuo ha adquirido un estatus propio que, sin negar las bases propias del derecho internacional, las interpela, haciendo favorable el respeto de sus derechos a todo nivel. A partir de ello, se puede ver que la evolución de ambos conceptos, soberanía y derechos humanos, se ha ido consolidando y compatibilizando a partir de distintas manifestaciones, que incluyen también, los aportes jurisprudenciales de distintos tribunales internacionales.

A modo de conclusión, debe señalarse que estas tensiones jurídicas trasladadas al caso de estudio en concreto, evidenciarán que la soberanía hoy en día no puede entenderse de manera absoluta. Hoy en día resulta cuestionable apelar a la soberanía para justificar la construcción de un muro fronterizo, con lo cual los Estados tendrían que examinar previamente todas las contingencias en materia de protección al individuo, así como las consideraciones jurídicas que lo vinculan. Por solo citar un ejemplo actual, la presencia de un muro fronterizo podría conculcar el derecho a la vida o integridad como se ha documentado en la ciudad de Ceuta (frontera de España con Marruecos), en donde muchas personas han fallecido al intentar cruzar dicho muro, ya sea por los efectos de las alambradas, como por los sistemas de electricidad (Público, 16 de abril de 2018).

\section{6. ¿Puede un muro fronterizo generar responsabilidad internacional del Estado que lo construye?}

Un aspecto final que da cuenta de las consecuencias de la presencia de un muro fronterizo en el territorio de un Estado es la determinación de responsabilidad estatal por hechos internacionalmente ilícitos. En este acápite se analizará qué elementos y hechos deben de concurrir para estar frente a responsabilidad internacional. De acuerdo al proyecto de artículos sobre responsabilidad del Estado por hechos internacionalmente ilícitos, elaborado por la Comisión de Derecho internacional, para abordar la responsabilidad internacional deben mediar dos elementos.

De un lado, el hecho ilícito internacional, que hace referencia a la contravención a una obligación internacional, sin importar su naturaleza u origen, vale decir, convencional o consuetudinaria ${ }^{2}$. En el caso en específico, se ha planteado en el ejemplo del caso de Ceuta, que podría darse la vulneración del derecho a la vida o integridad de un individuo que intenta cruzar el muro fronterizo. Dependiendo de la jurisdicción que analice una eventual demanda por la vulneración de tal derecho, se podría concluir que

\footnotetext{
2 Esta disposición se encuentra contenida en el artículo 12 del proyecto y señala que existe una «violación de una obligación internacional cuando un hecho de ese Estado no está en conformidad con lo que de él exige esa obligación, sea cual fuere el origen o la naturaleza de esa obligación».
} 
la conducta descrita en una disposición como el PIDCP o el CEDH, como tratado de derechos humanos del sistema europeo, por ejemplo, podría ser contravenida.

En ese sentido, debe tomarse en consideración que tal incumplimiento guardaría relación con una norma de derecho internacional, como por ejemplo el respeto y garantía del derecho a la vida, o a la integridad. En ese sentido, el Estado infractor no podría apelar a su normativa interna, pues un principio básico del derecho internacional es su primacía frente al derecho interno (artículo 27 de la Convención de Viena sobre el derecho de los tratados de 1969).

De otro lado, se encuentra el criterio de atribución el cual guarda relación con que la disposición vulnerada (los derechos enunciados) sea efectivamente oponible, y por lo tanto exigible al Estado que construyó el muro. A partir de dicha constatación, su incumplimiento por acción u omisión tendrá como consecuencia la responsabilidad internacional.

$\mathrm{Al}$ respecto, no cualquier acción u omisión le será directamente atribuible al Estado, sino solo aquellas que sean conducidas por órganos que actúen en representación del mismo, conforme se encuentra establecida en su fuero interno. En el caso concreto, se deberá constatar si determinado órgano o funcionario ha actuado en representación del Estado.

Por último, como se ha podido revisar en la investigación que da cuenta sobre los muros fronterizos en la actualidad, la gran mayoría de los mismos han sido erigidos a partir de órdenes gubernamentales, o de funcionarios estatales con capacidad para la toma de decisiones. Este hecho que confirmaría la presencia del criterio de atribución, y por lo tanto, el Estado que construyó el muro fronterizo se convertiría en infractor, generando responsabilidad internacional y activando la obligación de reparar.

\section{Conclusiones}

A modo de conclusión, se comenzará haciendo énfasis en que la construcción de muros fronterizos no corresponde a un hecho o fenómeno actual. Todo lo contrario, ha estado presente incluso desde siglos antes de Cristo, y da cuenta que, desde tiempos remotos, la noción de defensa y protección territorial estaba presente entre los diferentes grupos de personas.

De esta manera, en los contextos fronterizos ha aparecido una multiplicidad de nomenclaturas que se han ido acuñando a los diversos objetos de división fronteriza. Para todos ellos, se ha empleado el de muro fronterizo, en atención a lo señalado por la CIJ en la opinión consultiva sobre la construcción de un muro en territorios ocupados palestinos. 
Así, en un contexto fronterizo se pueden poner de manifiesto las diversas dinámicas e interacción de las comunidades que ahí radican. Estas dinámicas pueden estar marcadas por un profundo intercambio, o una situación de conflicto, situación que hará más o menos hostil la presencia de un muro en la frontera.

A ello debe de sumársele el fenómeno de la globalización. Así, tras la caída del muro de Berlín, las fronteras en el mundo tendieron más hacia la convergencia, es decir, hacia la cooperación e interdependencia, y quizás el mejor ejemplo de ello ha sido (y sea) el establecimiento de la zona Schengen en el continente europeo. Sin embargo, no todo fue positivo en este periodo. Si bien la globalización aportó mucho en la apertura fronteriza entre los Estados, no es menos cierto que tuvo también una repercusión negativa en determinados ámbitos, cuyo impacto se sintió más en la desigualdad social y económica que experimentaron algunos Estados. Precisamente, estos nuevos brotes conflictivos dieron lugar a que los Estados nuevamente amurallen sus fronteras.

Conforme se ha señalado, las dos principales razones por las cuales los Estados han vuelto a optar por la construcción de muros fronterizos son: evitar la inmigración y protegerse frente a una eventual agresión, que comúnmente han sido ataques terroristas. Estos factores evidencian que, en un mundo globalizado, la construcción de muros fronterizos se erige como una de sus contradicciones más notorias, pues lejos de coadyuvar a la integración e interdependencia, ha significado un retorno a una visión clásica de Estado, soberanía y seguridad nacional en donde las fronteras eran espacios altamente rígidos y cerrados.

Es en este contexto que se contraponen dos conceptos, de un lado el de soberanía estatal, y de otro lado el de derechos humanos, marcado por el proceso de humanización del derecho internacional. En esa línea, este artículo ha propuesto una aproximación hacia una visión que propone la compatibilización de ambos conceptos, con la finalidad de señalar que hoy en día resultaría cuestionable la apelación a la soberanía para justificar la construcción de un muro fronterizo, toda vez que la sola presencia de este podría vulnerar los derechos del individuo.

Finalmente, importa destacar que, frente a la constatación de la violación de algún derecho humano surgido a partir de la presencia de un muro fronterizo, los Estados podrían incurrir en responsabilidad internacional cuando concurran dos requisitos. El primero de ellos, que haya un hecho internacionalmente ilícito, que implique la violación de una obligación internacional, por ejemplo, el derecho a la vida o integridad. El segundo elemento, es que tal hecho sea atribuible al Estado ya sea por una acción u omisión; es decir, que algún funcionario del aparato estatal haya permitido la configuración de tal acto. Esta última consideración se vería satisfecha, toda vez 
que son los propios órganos del Estado los que, en la gran mayoría de casos, han dispuesto la construcción de tal objeto.

En ese contexto, resulta fundamental ampliar el análisis sobre la presencia de un muro en la frontera que proponga una aproximación jurídica y que permita evaluar caso a caso si estos son o no compatibles con la protección de individuo.

\section{Referencias bibliográficas}

Antoñanzas, M.A. (28 de febrero de 2019).Conflicto por Cachemira: ¿por qué India y Pakistán pelean por el territorio? CNN Español. Recuperado de https://cnnespanol.cnn.com/ video/cachemira-conflicto-pakistan-ira-pkg-miguel-angel-antonanzas-explainer/

Arango, J. (2007). Las migraciones internacionales en un mundo globalizado. En Vanguardia dossier, 22. Recuperado de https://webs.ucm.es/info/gemi/descargas/ articulos/45ARANGO_Las_Migraciones_Mundo_Globalizado.pdf

Brown, W. (2010). Walled States, Waning Sovereignty. Nueva York: Zone Books.

Cançado Trindade, A.A. (2006). Humanização do Direito Internacional. Belo Horizonte: Ed. Del Rey.

Cançado Trindade, A.A. (2007). Hacia el nuevo derecho internacional para la persona humana: manifestaciones de la humanización del derecho internacional. Revista da Facultad de Direito da UFMG, 50, 44-61.

Carrillo Salcedo, J. A. (2000). Derechos humanos y derecho internacional. Isegoría. Revista de Filosofia Moral y Politica, 22, 69-81. https://doi.org/10.3989/isegoria.2000.i22.522

Cassese, A. (1993). Los derechos humanos en el mundo contemporáneo. Barcelona: Ed. Ariel.

Chomsky, N. (2005). El proceso llamado globalización. Flacso Ecuador. Recuperado de https://flacsoandes.edu.ec/web/imagesFTP/1265837306.El_proceso_llamado_Globalizacion.pdf

Corte Internacional de Justicia - CIJ (2004). Opinión consultiva A/ES-10/273 Consecuencias juridicas de la construcción de un muro en el territorio palestino ocupado. Recuperado de https://www.icj-cij.org/files/advisory-opinions/advisory-opinions-2004-es.pdf

Diesbach de Rochefort, N. (2002) Frontera: ¿̨Muro divisorio o tejido de relaciones? Estudios Fronterizos, 3(5), 9-42. Recuperado de http://www.scielo.org.mx/pdf/estfro/v3n5/ v3n5a1.pdf

Enrico, A. (2019). Los muros fronterizos en la era de la globalización: una aproximación desde el Derecho internacional (tesis de pregrado). Pontificia Universidad Católica del Perú, Lima, Perú. Recuperado de http://tesis.pucp.edu.pe/repositorio/ handle/20.500.12404/13499

Fidler, D. (2004). International Law and Weapons of Mass Destruction: End of the Arms Control Approach? Maurer School of Law: Indiana University. Faculty articles 417. Recuperado de https://www.repository.law.indiana.edu/cgi/viewcontent. cgi?article $=1417 \&$ context $=$ facpub

Gargantilla, P. (2016). Enfermedades que cambiaron la historia. Madrid: Editorial La Esfera de los Libros. 
Hecht, E. (24 de julio de 2014). Franja de Gaza: cómo creció la red de túneles de Hamas. BBC Mundo. Recuperado de https://www.bbc.com/mundo/ noticias/2014/07/140723_hamas_tuneles_gaza_ac

Lisón Tolosana, C. (1994). Antropología de la frontera. Revista de Antropología social, 3, 75-103.

Martínez, O.J. (1994). Border people: life and society in the US - Mexico borderlands. Tucson: University of Arizona Press.

Meron, T. (2006). The humanization of international law. The Hague: Ed. The Hague Academy of International Law.

Montero, J.L. (2012). Breve historia de Babilonia. Madrid: Ed. Nowtilus.

Nagan, W. y Hamer, C. (2004). The Changing Character of Sovereignty in International Law and International Relations. UF Law Faculty Publications: University of Florida Levin College of Law, 43, 141-187. Recuperado de https://scholarship.law.ufl.edu/cgi/ viewcontent.cgi? article $=1592 \&$ context=facultypub

Novak, F. y García-Corrochano, L. (2016). Derecho Internacional Público. Tomo II, Vol. 1. Lima: Thomson Reuters.

Ortega, A. (2006). Los muros de la globalización. Foreign Policy Edición Española, 13, 3-4.

Público (16 de abril de 2018). Investigan la muerte de dos migrantes hallados en Ceuta tras saltar la valla. Recuperado de https://www.publico.es/sociedad/valla-ceuta-investiganmuerte-migrantes-hallados-ceuta-saltar-valla.html

Riepl, M. (10 de julio de 2017). ¿Cómo es realmente el polémico muro que Ecuador construye en la frontera con Perú? BBC Mundo. Recuperado de https://www.bbc.com/ mundo/noticias-america-latina-40534421

Rule of Law in Armed Conflicts - RULAC (2018). Non-international armed conflicts in Yemen. Geneva Academy. Recuperado de http:/www.rulac.org/browse/conflicts/ non-international-armed-conflicts-in-yemen

Salmón, E. (2014). Curso de Derecho Internacional Público. Lima: Fondo Editorial de la Pontificia Universidad Católica del Perú.

Shelley, F. M. (2015) The World's Population: An Encyclopedia of Critical Issues, Crises, and Ever-Growing countries. Oxford: Ed. ABC-CLIO.

Vallet, E. (ed.) (2014). Border, fences and walls: state of insecurity? Burlington, VT: Ashgate Publishing.

Villegas, P. y Semple, K. (1 de febrero de 2019). Estados Unidos empieza a devolver a los solicitantes de asilo a México. The New York Times. Recuperado de https://www.nytimes. com/es/2019/02/01/politica-solicitud-de-asilo-trump/

Zapata-Barrero, R. (2012). Teoría política de la frontera y la movilidad humana. Revista Española de Ciencia Política, 29, 39-66.

Recibido: 4 de abril de 2019

Aprobado: 19 de agosto de 2019 